\title{
LUYS DE CAMOENS EN LA PROSA DEL LUNAREJO Y EN LA POESIA DE CAVIEDES
}

\author{
Estuardo Nuñez \\ (Diretor da Bib.ioteca Nacional do Peru)
}

\begin{abstract}
Después de su muerte relativamente temprana, la fama de Camoens empezó a irradiar a todo el mundo conocido y con su celebridad se difundió también la fama de Portugal y del esfuerzo de sus hombres en favor de la Humanidad entera, beneficiaria directa de la hazañosa aventura descubridora de Bartolomé Díaz y de Vasco de Gama. De tal suerte, Camoens compartió mucho del interés de Europa por los nuevos descubrimientos de los portugueses, pues el gran poeta había intuído el conflicto esencial de su época y de su patria. Vislumbró, como dice su biógrafo Reinhold Schneider, en la grandeza del imperio portugués, también el germen del infortunio y de la disolución (1)
\end{abstract}

La crítica literaria portuguesa, al impulso todavía de la antigua retórica, exaltó a Camoens ya desaparecido en términos cálidos y superlativos. A esa tarea habría de entregarse un discutido estudioso de la historia y literatura portuguesas, de vasta obra, que fue Manuel de Faria y Sousa (1590-1649), contemporâneo de Camoens y su más ferviente admirador y traductor al castellano. Con un criterio providencialista ap.icado a la apreciación de la poesía, Faría escribió un libro titulado Los Lusíadas de Luis de Camens, príncipe de los poetas de Esparña, (2)

Para colocar a Camoens en el sitial de genio dotado de potencias poéticas divinas y para proclamarlo como el primer poeta del mundo hispano-portugués, recurrió al arte de rebajar la gloria de sus congéneres de la península, inflando de virtudes a Camoens y recortando en las suyas a los contemporáneos del siglo de oro español, sobre todo a Luis de Góngora y Argote, considerado en ese

(1) - Schneider, Reinhold, Camoens (Das Leiden des Camoens), Trad. en castellano, Buenos Aires, Ediciones Peuser, 1952.

(2) - Faria y Sousa, Manuel, Los Lusiadas de Luis de Camoens, principe de los poetas de España, comentados por —, Madrid, por Juan Sánchez a costa de Pedro Coello, 1639, 4 tomos en folio. 
momento el genio promotor de una corriente de gran auge: el cu'teranismo barroco. La reiterada fobia denigratoria contra Góngora, emprend.da por Faria y Sousa, habría de encontrar en el Peru un contradictor de agudeza singular: Juan de Espinosa Medrano llamado "El Lunarejo" quien se ocupa de los comentos de Faria cuando ya éste ni Góngora vivían.

Espinosa Medrano (1632-1688), nacido y formado en el Cuzco, extraordinario lingüista y clérigo de vigorosa y erudita oratoria y de singu ar capacidad filosófica, publica por primera vez en 1662, su Apologético en favor de don Luis de Góngora (3) para defender a Góngora de la furiosa crítica de Manuel de Faria y Sousa en la cual, según dice Espinosa Medrano, "para ensalzar a su Camoens echa a rcdar los Virgilios, los Horacios, los Píndaros, los Homeros, los Plautos y Menandros" (p. 134) y desde luego a Góngora, príncipe de los poetas de España, reconocido y admirado como tal por Espinosa Medrano y también en nuestra época como precursor de un nuevo sentido raigal de la poesía.

Frente a los embates de Faria y de su intención peyorativa de parangonar en descrédito a Góngora con Virgilio y otros latinos, El Lunarejo acrece su admiración por el poeta español y proclama:

"que la elocuencia latina tiene mucho que aprender de la gongorina, mucho que imitar de sus primores, mucho que admirar de su espíritu" (p. 113)

Condena en Faria sus interpretaciones forzadas acerca de pretendidas simbo izaciones del poema que éste deduce a su gusto y capricho, y que le atribuye disparatadamente a Camoens y combate El Lunarejo sus falacias y arbitrarias disquisiciones sobre vocabulario, etimologías, figuras y tropos.

Pero El Lunarejo en contras'e con su opositor, no pierde el equiquilibrio y la ponderac.ón del buen crítico al reconocer:

"Qué de estudio le costaría el comentar aquello del Camoens: de tecida seda. Donde dice, que en aquel coludir de sonidos, cida seda, significó el poeta el ruido de la seda, que con su tejido apretado suena cida seda. Como el tafetán, que en su mismo vocablo dice su sonido tafe tafe. Esto es cosa grande."

(3) - Espirosa Medrano, Juan de, "El Lunarejo", Apologético en favor de Don Luis de Góngora, Lima, 1662.

Citamos en lo sucesivo por la edición moderna: V García Calderón, El apogeo de la literatura colonial, París, Descleé de Brower. 1938, p. 57135 
Tampoco oculta e! Lunarejo su admiración por Camoens, según evidencian éstas y otras citas, y no lo mezcla o confunde con el blanco de su aguerrida saeta dirigida a Faria.

Pero le merece al Lunarejo la más viva reprobación la trase de Faria que contiene el meollo de su fundamento crítico.

\author{
"Este rarísimo poeta (Camoens) fue singularmente asistido \\ de Espíritu Divino" (p. 173)
}

Esta es doctrina crítica transida de providencialismo que lo lleva al extremo de equiparar o comparar las Sagradas Escrituras con Los Lusíadas.

Faria no escindía los conceptos de letras "humanas" y letras "divinas", o sea que confundía literatura con teología o jugaba irresponsablemente con esos conceptos.

Espinosa corrige el yerro y sostiene que lo sagrado no requiere más adorno en razón de su carácter de misterio, pero el arte requiere como creación humana de "una sal, de un concepto, de un donaire o gracia" y e'lo no corresponde a la esfera de lo divino sino de lo estético.

Reconoció, sin embargo, Espinosa Medrano alguna virtud a Faria, recordando que había escrito libros de historia sobre los portugueses y sus hazañas por el mundo, al escribir sus tomos acerca de la acción de los lusitanos en Asia, Africa y Europa, y agrega:

"Bueno es Faria para contar;

nunca empero lo será para cantar.

"Nególe el cielo felicidad para los versos;

aunque le concedió el genio de historiador" (p. 175)

y así en el Comento de Camoens, por Faria encuentra El Lunarejo que io mejor es lo que narra y agrega:

"Más fácil juzgo la senda para la fama en quien camina por el llano del érase que se era (la narración) que en quien vuela por las cumbres del metro y las esferas de la cítara (la poesía)" (p. 174)

En defensa de Góngora y a propósito de Camoens, Espinosa Medrano escribió el primer ensayo de crítica moderna en la América colonial del XVII. En esa línea creadora es el precursor del ensayo interpretativo y polémico, tal vez con cierto cerrado discurrir conceptista calcado de Gracián. Pero exhibió una lúcida concien- 
cia estético-'iteraria que se transparenta en el donaire y justeza con que se antecipa a una crítica anti-dogmática y a la gallardía con que arremete contra el providencialismo ingenuo y cómodo del crítico portugués. Señala como absurdo el intento de Faria al criticar a Góngora extrayendo ejemplos poéticos fragmentarios fuera de su contexto restante y sin "la trabazón que en sus lugares gozaban" Respalda el fuero de la más noble poesía al defender el tropo y la informalidad lógica de la frase. "Tan lejos está la inversión de las voces -dice- tan distante de viciar los versos, que en ellos no es tropo sino alcurnia; no es afeite sino faición; no es defecto sino naturaleza"

En tal forma, Espinosa Medrano trajo a nivel terreno de la pura teoría estética !a crítica y el elogio de Camoens que Faria con razones extra-literarias y de torcida teología había subido a un cielo ramplón y convencional.

Y por cierto, El Lunarejo no iba a incurrir en lo mismo que Faria. Al contrario, para defender a Góngora no hubo menester de disminuir a Camoens y antes bien, reconoció sus innegables méritos y constituyó una de las primeras voces críticas - ya los poetas lo habían antecedido en el elogio lírico- que se elevaron en el Nuevo Mundo para reconocer, sin parangones insustanciales y forzados, cl alto rango de la poesía del autor de Los Lusíadas.

\section{Camoens y Caviedes}

Hay un poeta de esta época el más genuinamente popular de ese momento de mediados del XVII el primero que se sacudió de la hegemonia de las Academias y el primero que pulsa el hablar desenfadado del pueblo, la sátira violenta y también el lirismo profundo entre melancólico y sentimental, que se acerca a la lírica de Camoens y se identifica plenamente con ella. Es Juan del Valle y Caviedes (1650?-1967?) andaluz avecinado en Lima, pero viajero empedernido por casi todo el Perú.

$\mathrm{N}_{0}$ es el satírico Caviedes - enemigo de médicos y curanderos - el que en esta conjuntura interesa, sino el sentimental, el autor de romances y sonetos de amor, que hubo de beber en las sonoras fuentes de Garcilaso, el toledano, y que como todos los poetas de su época - inclusive el perínclito Camoens - se nutrió abundantemente de los clásicos latinos Virgilio y Horacio y en p’ano menos notorio, del italiano Petrarca. Por eso Augusto Tamayo Vargas ha podido advertir que "los romances amorosos de Caviedes tienen un claro y definido entronque con Camoens, tan seguido en los albores de ese siglo XVII" (4) Y ese entronque pudo ser en

(4) . - Tamayo Vargas, Augusto, Literatura Peruana, vol. I, Lima, Imp. D. Miranda, 1953, p. 230. 
parte indirecto y en parte también directo y no sólo con los romances sino también con los sonetos, como se advierte en el siguiente poema de Caviedes que revela bien a las claras su progenie:

\section{Catorce definiciones al Amor}

Amor es nombre sin deidad alguna,

Un agente de el ser de cuantos nacen,

Un abreviar la vida a los que yacen,

Un oculto querer a otra criatura.

Un fantasma asombro de hermosura.

Una falsa opinión que al mundo esparcen.

Un destino de errar en cuanto hacen.

Un delirio que el gusto hace cordura.

Fuego es de pedernal si está encubierto.

Aire es si a todo baña sin ser visto.

Agua es, por ser vicio de la espuma.

Una verdad, mentira de lo cierto.

Un traidor que adulando está bien quisto,

El es enigma y laberinto en suma

La fuente pudo ser el "soneto de Amor" de Camoens que dice:

Amor es fuego que arde sin arder;

es herida que daña sin herir;

una satisfacción que hace sufrir;

un dolor que transforma sin doler;

un no querer mejor que un bien querer;

y sólo entre la gente discurrir;

es un uno cesar alegre de reir

y pensar que ganamos al perder.

Es un estarse preso a voluntad

y servir a quien vence el vencedor

con quien nos manda al fin tener lealtad;

¿Mas cómo expresar puede en su favor

el pobre corazón conformidad,

siendo así tan contrario al mismo amor?

(5). - Inserto en Obras de Caviedes, publicadas con introducción y notas por Rubén Vargas Ugarte S.J., Lima, 1947, - El texto cotejado y depurado por Vargas Ugarte, resulta más propio e inteligible que el ofrecido por Luis Fabio Xammar en: Fenix, N.o 3, Lima, ler semestre de 1945.

(6). - Camoens, "Soneto de Amor", transcrito tardíamente en: El Perú, N. 302,29 de abril de 1971, p.5. consignado antes en todas las recopilaciones de poesia lírica de Camoens. 
Por lo demás, el estudio comparativo entre los 15 Romances amorosos (7) (que difieren notoriamente de las poesías satíricas) de Caviedes con los Sonetos de Camoens - originariamente escritos unos en españo! y otros en portugués - demuestra una innegable semejanza de imágenes y giros poéticos. No hay plagio ni imitac.ón directa. Los diferencia un diverso tratamiento de igua es tópicos de amor, un tanto petrarquescos, pues el italiano los influyó por igual así como a todos los poetas de la época.

\section{Dice Caviedes en su Romance IX:}

Lo mismo ¡Ay de mí! decía, sucede a mis pensamientos, pues con suavidad de agua ablandar peñas pretendo.

Y Camoens en su soneto 14:

Los montes parecia que abiandaba con las penas y angustias que decía.. (Liso)

En el Soneto 27, Camoens dice:

Males, que en mi ruina os conjurasteis, ¿Hasta cuándo tendreis tan duro intento?

Si dura porque dure mi tormento, Básteos cuanto ya me atormentasteis.

Y sigue Caviedes la misma tónica en su Romance I, aunque con sentimiento más estoico:

Penas, sed más rigorosas para alivio del que os pasa, que el cochillo que más corta menos aflije al que mata

Camoens dice en su Soneto 68:

$Y$ si esa condición cruel y esquiva que me deis ley de vida no consiente. dadme al menos, señora, ley de muerte.

(7). - Caviedes, Juan del Valle y, "15 romances amorosos" insertos en: V García Calderón, El apogeo de la literatura Colonial, tomo $\mathrm{V}$ de la Colección de la Cultura Peruana, París, Descleé de Brower, 1938. 
Y si ni éste me dais, justo es que viva,

sin saber cómo vivo tristemente;

mal al menos contento con mi suerte.

Y dice Caviedes en su Romance II, en plano semejante de "Amor causa muerte":

Morir quiero de los males

de puro vivir con ellos,

que quien de tristeza enferma

se ha de curar con veneno.

Mueran de mal entendidos

mis cobardes pensamientos

que quien sin conocer mata

hace su delito menos.

Hay correspondencia indudab'e entre otros versos:

Lucinda ¿por que me has dicho que te viese el otro día, Sabiendo no puede ser porque ciega el que te mira?

(Caviedes, Romance X)

Y semejanza:

sucesivamente quiero

teneros siempre en el alma, porque se engaña a sí propio el que las penas engaña

(Caviedes, Romance I)
Y voy de día en día, de año en año, en pos de un no se qué, y en pos de

un nada,

Que cuando más me acerco menos

veo.

(Camoens, Soneto 110)

de falsas esperanzas, qué pretendo?

¿Por qué si nací libre me cautivo? $Y$ pues lo quiero ser ¿por qué no

¿Cómo me engaño más con quiero?

desengaño?

(Camoens, Soneto, 112)

\section{Y desesperanza:}

No maten sino den vida, porque es proceder tirano causar el daño y que no quieran remediar al daño

(Caviedes, Romance III)
Si ya desesperé, ¿qué mas espero?

Y si aun espero más, ¿ por qué

no vivo?

Si vivo, ¿por qué causa aquestos

daños?

(Camoens, Soneto 112) 


\section{Y contradicción:}

Yo amo con extremo y me aborrecen con extremo, $y$ ha de volverse al contrario porque llego a lo postrero.

(Caviedes, Romance IV)
Triste de mi, ique a un tiempo lloro y rio!

iEspero, quiero, temo y aborrezco! Juntamente me alegro, $y$ me entristesco;

Confío de una cosa, y desconfío. (Camoens, Soneto 150)

Es sin duda interessante anotar el tratamiento del tema igual del triste pastor y del mísero zagal:

En el regazo de un olmo

estaba un triste pastor

pensativo y sol'ozando

....

así decía a las flores;

..... $\quad \ldots$

Flores, si sabeis de amor sentid mi desprecio, en tanto que con el lloro que vierto vuestro tronco riego en pago.

(Caviedes, Romance III)
Las peñas retumbaban al gemido del mísero zagal, que lamentaba El dolor, que a su alma lastimaba, De un obstinado desamor nacido.

Responden a mi llanto duras peñas: jay de mí! (digo) brama el mar y gime;

Los ecos suenan de tristeza llanos; "Y tú, por quien la muerte en mí se imprime, De oir las ansias más te desdeñas; y cuando lloro más, te ablando menos!"

(Camoens, Soneto 164)

Y ambién el motivo de los ojos que hieren:

Con las saetas de tus ojos

flechas con tal puntería, qui mi corazón partieron más que las flechas de tus niñas.

(Caviedes, Romance V)
¡Oh, si ya tu esquvez me permitiese

Pue al ver, oh Ninfa, tu semblante hermoso, A manos de tus ojos yo muriese!

(Camoens, Soneto 213 en castellano)

\section{Y otros aspectos poéticos semejantes:}

Si hubiera sabido, ninfa, tu venganza, en mi venganza por quererte más te hubiera querido con menos ansia.

(Caviedes, Romance V)
Si gloria de mi pena en ti se siente; Derrama en mí tus iras desamando; Que al ofenderme más, yo más te quiero.

(Camoens, Soneto 215, en castellano) 
Suspiro por apagar

de amor el activo fuego,

Que aunque mucho aire lo apaga

si el poco le da fomento.

(Caviedes, Romance IV)

Selvas, a quejarme vengo

Troncos, escuchad mis penas

consuelo os pido a vosotros

como si con ella hablara

pues con silencio o dureza

responde siempre a mis ansias.

(Caviedes, Romance XII)
Si el fuego que me enciende,

consumido

De algún más suelto Acuario

ser pudiese;

Si el alto suspirar se convirtiese

En aire por el aire desparcido:

(Camoens, Soneto 219 en castellano)

Cantando mi dolor llora mi muerte;

Porque hasta el hueco monte sin

sentido

Suelta su ronca voz por consolarme.

(Camoens, Soneto 226 en castellano)

Muriendo estoy por morir, si contraria me persigue una voluntad alegre con una memoria triste. $\mathrm{Ni}$ con mis penas acabo ni acabo de persuadirme, que lo propio que me alienta es lo mismo que me aflige.

(Caviedes, Romance VII)

Si de penas de amor sois maltratados, ¿Por qué buscais a amor y sus dolares? $\mathrm{Y}$ si los teneis a estos por favores, ¿Por qué de ellos hablais como agraviados? (Camoens, Soneto 251)

Lo que Camoens había logrado con Petrarca, o sea refundirlo artísticamente, lo realiza Caviedes con Camoens, y así se cump'e aquello a que aludía Helmuth Hatzfeld, de que "si no se llega al plagio, una discreta imitación ofrece oportunidad al poeta imitador de reve'ar su más íntima originalidad" (8)

(8). - Hatzfeld, Helmuth, Bibliografía crítica de la nueva Estilistica, Madrid, Edit. Gredos, 1955, p. 79. 